\title{
Severe polyhydramnios as neonatal presentation of Bartter's syndrome type IV
}

Mariana Alvarenga Hoesen Doutel Coroado 1

iD https://orcid.org/0000-0002-1169-2482

Joana Manuel Silva Fernandes Lopes Tavares 2 iD https://orcid.org/0000-0002-3776-4923

António Gonçalo Inocêncio Vila Verde 3

iD https://orcid.org/0000-0002-5818-5672

Maria do Céu Pinhão Pina Rodrigues 4

iD https://orcid.org/0000-0002-9732-3433

\author{
Liane Maria Correia Rodrigues da Costa Nogueira Silva 5 \\ iD https://orcid.org/0000-0003-3827-0148 \\ Sara Maria Mosca Ferreira da Silva 6 \\ iD https://orcid.org/0000-0002-8478-9226 \\ Maria do Céu Rocha Mota 7 \\ (iD) https://orcid.org/0000-0001-9957-3471 \\ Jorge de Sousa Braga 8 \\ iD https://orcid.org/0000-0003-1824-7426
}

\footnotetext{
1,8 Departamento de Obstetricia e Ginecologia. Centro Materno-Infantil do Norte Dr. Albino Aroso. Centro Hospitalar Universitário do Porto. Porto, Portugal. E-mail: marianacoroado@gmail.com

2 Departamento de Nefrologia. Centro Hospitalar Universitário do Porto. Porto, Portugal.

3,4 Divisão deMedicinaMaterno-Fetal. Centro Materno-Infantil do Norte Dr. Albino Aroso. Centro Hospitalar Universitário do Porto. Porto, Portugal.

5 Divisão de Nefrologia Pediatrica. Centro Materno-Infantil do Norte Dr. Albino Aroso. Centro Hospitalar Universitário do Porto. Porto, Portugal.

6 Departamento de Pediatria. Centro Materno-Infantil do Norte Dr. Albino Aroso. Centro Hospitalar Universitário do Porto. Porto, Portugal.

7 Departmento de Neonatologia e Cuidados Intensivos Pediatricos. Centro Materno-Infantil do Norte Dr. Albino Aroso. Centro Hospitalar Universitário do Porto. Porto, Portugal.
}

\begin{abstract}
Introduction: Bartter's syndrome comprises a heterogeneous group of inherited salt-losing tubulopathies. There are two forms of clinical presentation: classical and neonatal, the most severe type. Types I and II account for most of the neonatal cases. Types $I I I$ and $V$ are usually less severe. Characteristically Bartter's syndrome type IV is a saltlosing nephropathy with mild to severe neonatal symptoms, with a specific feature sensorineural deafness. Bartter's syndrome type IV is the least common of all recessive types of the disease.

Description: the first reported case of a Portuguese child with neurosensorial deafness, polyuria, polydipsia and failure to thrive, born prematurely due to severe polyhydramnios, with the G47R mutation in the BSND gene that causes Bartter's syndrome type IV.

Discussion: there are few published cases of BS type IV due to this mutation and those reported mostly have moderate clinical manifestations which begin later in life. The poor phenotype-genotype relationship combined with the rarity of this syndrome usually precludes an antenatal diagnosis. In the presence of a severe polyhydramnios case, with no fetal malformation detected, normal karyotype and after maternal disease exclusion, autosomal recessive diseases, including tubulopathies, should always be suspected.

Key words Neonatal, Bartter syndrome, Sensorineural deafness, Polyhydramnios, Premature delivery, Case report
\end{abstract}

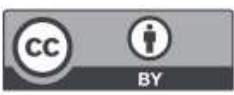




\section{Introdução}

Bartter's syndrome (BS) is a genetic tubulopathy, characterized by hypokalemia, metabolic alkalosis, and secondary hyperaldosteronism with normal to low blood pressure due to the renal loss of sodium. Accordingly to the severity and age of presentation, Bartter's syndrome has been classified as: Neonatal BS (ABS) or classical BS (CBS). ABS onset can be intra-uterine or in the neonatal period, and is characterized by urinary concentration defect, with polyuria and loss of sodium, potassium and chloride, and nephrocalcinosis. CBS presents later in life and generally has milder symptoms. 1,2

Globally, BS is a rare hereditary disorder, with an estimated prevalence of 1,2 per million people. Since the first description of the syndrome was in 1962, the pathophysiology of BS has been intensively studied, and BS can be classified based on the channel and the gene mutated that affects its function. Mutation of several genes may result in BS, which is known for its genetic heterogeneity. Bartter's syndrome cannot be corrected (except by kidney transplantation). Thus, treatment, which must be lifelong and, is aimed to correct volume and electrolyte disturbances. 3

\section{Description}

A 31-year-old healthy pregnant woman was referred to the prenatal diagnosis department at the hospital due to polyhydramnios diagnosed at 30 weeks of an otherwise, uneventful first gestation of a nonconsanguineous couple. The detailed ultrasound scan performed at 32 weeks at the center revealed: stomach and bladder were well represented, cephalic measurements near the 95th percentile, decreased fetal movements with apparent abnormal posturing of the extremities. At that moment, shortness of breath and painful uterine contractions were reported by the pregnant woman. The clinical situation was explained to the couple, who refused invasive testing, but agreed on blood collecting to perform thyroid function, serologic (TORCH infections) and indirect Coombs testing, which were all normal.

Due to severe polyhydramnios (deepest pocket of amniotic fluid of $20 \mathrm{~cm}$ ) and increasing symptoms, at 33 weeks of gestation, the pregnant woman was admitted for induction of fetal lung maturation with betamethasone, and amniodrainage $(1500 \mathrm{~mL})$, the latter needed to be repeated at 35 weeks of gestation (with additional $1400 \mathrm{~mL}$ drainage). The cytogenetic analysis of the amniotic fluid revealed a normal karyotype for a male fetus (46, XY).
At 36 weeks of gestation, an elective cesarean section was performed and a male newborn was delivered with 2880 grams (percentile 64) and Apgar index of 8/9/9. At physical examination, macrocephaly and peculiar facies (triangular shaped face, high forehead, asymmetric eyelids, retrognatism, low-set proeminent ears), axial hypotonia with peripheric hypertonia and abnormal posturing of the extremities: extended upper extremities, cubital deviation of the fists, persistently closed hands with camptodactily and discrete cavus feet were noted. The transient-evoked otoacoustic emissions screening test failed at birth. The newborn was discharged on the $15^{\text {th }}$ day after birth, to continue ambulatory follow-up in the outpatient clinics of neurodevelopmental, neuropediatrics and genetics. Neurosensorial deafness was confirmed and a cochleae implant was placed 1 month after birth.

Considering the described anomalies, deafness, muscle hypotonia and dysmorphic syndrome, neuromuscular and metabolic diseases were considered. Microarray was normal and gene panel testing for Marfan-like diseases was also negative. Congenital infection by cytomegalovirus was also excluded. After 7 months of age, weight gain deceleration was noted but the psychomotor development was unremarkable. The initial laboratory evaluation showed no alterations, with normal thyroid, celiac disease and organic acids screening tests. A sweat test was also performed: the first was positive, but a subsequent test was normal, as the stool elastase. No additional clinical manifestations suggested cystic fibrosis. A kidney evaluation was requested and the child was referred to a pediatric nephrologist. At the time of that appointment, the parents reported to have noticed, over the last months, the child's excessive fluid intake, awakening during the night with thirst. Severe polyuria (around $8 \mathrm{~mL} / \mathrm{kg} /$ day) and polydipsia (water intake around $2.5 \mathrm{~L} /$ day) were confirmed, a blood gas analysis revealed metabolic alkalosis with hypokalemia, the renal ultrasound revealed nephrocalcinosis and the diagnosis of Bartter syndrome was deemed to be very probable. This diagnosis was confirmed by the genetic sensorineural hearing loss workup that had already been performed, which identified homozygosity for a missense mutation in the BSND gene (G47R), which are Bartter's syndrome type IVacauses. Therapy with indomethacin and potassium chloride was initiated with a good response, including more adequate diuresis, decreased perception of polydipsia and increased appetite. 


\section{Discussion}

Bartter's syndrome (BS) is a rare hypokalemic saltwasting tubulopathy that affects the sodium chloride reabsorption in the medullary thick ascending limb of the loopof Henle, mimicking a loop diuretic as furosemide. This defect impairs urine concentration and increases sodium delivery to the distal tubule, leading to hypokalemia, metabolic alkalosis and secondary hyperaldosteronism with normal to low blood pressure. Genetic sequencing, to date, identified 7 genes linked to BS and BS-like syndromes (BSND, CASR, CLCNKA, CLCNKB, KCNJ1, MAGED2 and SLC12A1). BS type IV is caused by mutations in the BSND gene (on the chromosome 1p31), that affect the barttin function (BS type IVa), or due to the combined impairment of the CLCNKa and CLCNKb genes by digenic inheritance, resulting in a phenotype that mimics the one cause by defects in barttin (BS type IVb). Barttin acts as an essential beta subunit for the proper function of the voltage sensitive $\mathrm{ClC}-\mathrm{Ka}$ and $\mathrm{ClC}-\mathrm{Kb}$ chloride channels located in the basolateral membrane of renal tubules, as the thick ascending loop (TAL) of Henle, and in the potassium-secreting epithelia of the inner ear.1,2,4

After the successful gene identification, it was possible to divide this group of pathologies according to the nephron-segment involved, into loop disorders, distal convoluted tubule (DCT) disorders and combined disorders. 5

Regarding the clinical presentation, BS can also be divided in CBS and ABS. BS types I and II account for most cases of ABS and are the most severe. Their onset is frequently intra-uterine with polyhydramnios or in the early neonatal period with polyuria and life-threatening volume depletion, impaired development and high mortality if left untreated. Type III is frequently known as CBS and is usually clinically milder, first presenting during early adolescence. BS type IV is called ABS with sensorineural deafness, and its presentation is similar to types I and II, with the additional hearing deficit. Globally, BS is a rare hereditary disorder and BS type IV is the least common of all recessive types of Bartter syndromes. ${ }^{1-4}$

When we try to correlate the BS classical classification from type I to IV with the affected nephronsegment, conditions that affect the DCT, both DCT (BS types I and II) and combined disorders (BS type IV) are associated to polyhydramnios. 5

A case was reported of a neonate born prematurely due to polyhydramnios, homozygous for the G47R mutation of BSND gene. From our review of the literature, there are few published cases of BS type IV due to the G47R mutation of BSND gene (substitution of arginine for glycine at 47 amino acid position), and those reported mostly have moderate clinical manifestations, beginning later in life.6-8 Thus, to the best of our knowledge, the first reported case of BSND with such severe antenatal and neonatal manifestations from a non-consanguineous couple in Portugal.

On the examination, this child had a peculiar facies similar to that first reported by Miyamura et al. 6 in 2003, characterized by triangular shaped face, with prominent forehead, drooping mouth and protruding big ears. This facial appearance was first reported in a Japanese man, born of consanguineous parents, with the same G47R mutation, presenting sensorineural deafness, fatigue, weakness and polydipsia. In that case the diagnosis was only made at 28 years old, due to mild clinical manifestations, lacking the main features of ABS such as polyhydramnios, premature labor and salt-losing tubulopathy. The same phenotype, with peculiar facies, hearing loss, recurrent episodes of vomiting and dehydration since the first weeks of life, with hiypokalemic metabolic alkalosis with preserved renal function and failure to thrive had already been described in a series of 20 Costa Rican children in 1997, which shared a single common ancestor. In most of them, the pregnancy was complicated due to polyhydramnios and they were born prematurely. In the subset of patients that was later available for genetic testing, Kurtz et al. 9 identified a predominant mutation on the SCL12A1 gene, which is known to be cause of BS type I.4,6,9,10

Birkenhäger et al. 11 identified 7 different mutations in the BSND gene, and there have been reported more allelic variants. Besides, the same mutation may originate different clinical phenotypes, because of the individual variability in the genes of additional channels or in the modifying genes that regulate the expression. 4,11

One of the most notorious aspects of this case is the fact that the parents were unrelated: the mother was Brazilian and the father Portuguese, with no common ancestors found after family-trees review. Also both parents had no familiar history of deafness or renal disease. Since BS type IV has an autosomal recessive mode of transmission, it is mostly described in children born from consanguineous couples.

Polyhydramnios affects up to 2 percent in 100 pregnancies. $40 \%$ of these cases are considered idiopathic on the neonatal evaluation but actually, after birth, in around one-fourth an anomaly is diagnosed. Within the fetal causes, we should exclude chromo- 
somal/genetic anomalies, malformations (most missed in prenatal diagnosis are tracheoesophageal fistula, cardiac septal defects and cleft palate), metabolic diseases and congenital infection. Other causes include maternal or placental conditions (Table 1). Fetal anomalies are the most common etiology of severe polyhydramnios, while maternal causes and idiopathic factors are more frequently associated with milder cases. 12,13

In the presence of a severe polyhydramnios case, with no fetal abnormalities, normal karyotype and after maternal disease exclusion, autosomal recessive diseases, including tubulopathies, should always be suspected.

Genetic neonatal diagnosis of $\mathrm{BS}$ is possible with mutational analysis of genomic DNA from cultured amniocytes, but only if the mutation is already known, because of the delay in sequencing the genes. Nevertheless, if the suspicion is raised, biochemical analysis of the amniotic fluid can be helpful in the prediction of fetal BS. In our case, this test was not performed at the time because the amniodrainage BS was not suspected. This tubulopathy interferes with the establishment of a hypertonic medullar interstitial gradient necessary for water reabsorption in the collecting duct, which

Table 1

Polyhydramnios Etiology.

Fetal Conditions

Fetal anomalies

Maternal Conditions

Metabolic disorders

Infections

Diabetes Mellitus

Hypercalcemia

Placental Conditions

Chorioangioma
Trisomy 18

Trisomy 21

Turner syndrome

- Central nervous system: anencephaly, neural tube defects

- Gastrointestinal: duodenal or esophageal atresia, tracheoesophageal fistula, gastroschisis, omphalocele - Musculoskeletal: micrognathia, cleft palate, myotonic dystrophy, arthrogryposis, achondroplasia, thanotophoric dysplasia

- Respiratory: diaphragmatic hernia, congenital cystic adenomatoid malformation, chylothorax

- Cardiac: septal defects, arrhythmias

- Renal: tubular disorders

- Nonimmune or immune hidropsy

- Anemia: alloimmunization, parvovirus B19 infection, fetomaternal hemorrhage, alpha-thalassemia

- Fetal tumors: teratoma, hemangioma

- Twin-to-twin transfusion syndrome (multiple gestations)

Gaucher disease

Parvovirus B19

Cytomegalovirus

Toxoplasmosis

Gestacional diabetes

Pre-existing type 1 or type 2 diabetes

Idiopathic 
leads to increase fetal urine production, which, in turn, leads to amniotic fluid protein dilution. This dilution is not observed in polyhydramnios of nonrenal origin, such as maternal diabetes, Pierre Robin syndrome, chloride diarrhea or digestive tract atresia. In this case, if the suspicion of BS would have been raised during the prenatal period, an early diagnosis in the antenatal period could have been made, allowing for an earlier optimized management, with a better imbalance of volume and electrolytes, reduction of the risk of progression to nephrocalcinosis and improved growth.2,14

Some authors advocate the use of non-steroidal anti-inflammatory drugs (NSAIDs), as indomethacin in a low doses, starting before 32 weeks of gestation to inhibit prostaglandin production and slow the rate of amniotic fluid production, in the few cases diagnosed antenatally but further studies are needed to confirm the safety and efficacy of this approach, in arresting the progression of polyhydramnios and, consequently, preterm birth. After 32 weeks of gestation, due to the risk of premature closure of the ductus arteriosus, if NSAIDs are used, repeated ultrasound assessment for the development of tricuspid regurgitation is needed. 13

There are multiple proteins involved in salt reabsorption in the thick ascending limb of the loop of Henle, causing different types of Bartter's syndrome.

\section{References}

1. Giacomo C. Bartter syndrome. Orphanet [online]; 2001. [Accessed 15 Sept 2019]. Available from: https://www.orpha.net/data/patho/GB/uk-Bartter.pdf.

2. Cunha T, Heilberg I. Bartter syndrome: causes, diagnosis, and treatment. Int J Nephrol Renovasc Dis. 2018; 11: 291301.

3. Costa BM, Calado J, Navarro D, Nolasco F. Bartter syndrome - report of an unusual late presentation case and brief review.Port J Nephrol Hypert. 2016; 30 (1): 65-9.

4. Hamosh, A. BSND GENE.Online Mendelian Inheritance in Man [online]; 2001. [Accessed 15 Sept 2019].Available from: https://www.omim.org/entry/606412\#0008L.

5. Seyberth HW, Weber S, Kömhoff M. Bartter's and Gitelman's syndrome. Curr Opin Pediatr. 2017; 29 (2): 17986.

6. Miyamura N, Matsumoto K, Taguchi T, Tokunaga H, Nishikawa T, Nishida K, Toyonaga T, Sakakida M, Araki E. Atypical Bartter Syndrome with Sensorineural Deafness with G47R Mutation of the $\beta$-Subunit for ClC-Ka and ClCKb Chloride Channels, Barttin.J Clin Endocrinol Metab. 2003; 88 (2): 781-6.

7. Park CW, Lim JH, Youn DY, Chung S, Lim MH, Kim YK, Chang YS, Lee JH. Renal dysfunction and barttin expression in Bartter syndrome Type IV associated with a G47R
Also, the same transporter/channel can be affected by several mutations, and same genetic variant can lead to a different phenotypic manifestations. The poor phenotype-genotype relationship combined with the rarity of this syndrome usually precludes an antenatal diagnosis, which would allow early intervention and therapy. BS type IV was suspected and diagnosis was made because of the severe polyhydramnios, followed by a premature birth resulting in a neonate with polyuria, polydipsia, failure to thrive and neurosensorial deafness.

\section{Authors' contribution}

Coroado MAHD analyzed and reviewed the patient data and was the major contributor in writing the manuscript. Inocêncio G and Rodrigues MC played a major role in the prenatal management of the case. Correia-Costa L, Mosca S and R. Mota C conducted the case after the birth of the child and were responsible for the diagnosis. Tavares J, Rodrigues MC and Correia-Costa $\mathrm{L}$ performed a scientific revision and helped writing the manuscript. Tavares $\mathrm{J}$ and Coroado MAHD reviewed and edited the final manuscript, that all authors read and approved. mutation in BSND in a family. Clin Nephrol. 2011; 75 (Suppl.1): 69-74.

8. Kitanaka S, Sato U, Maruyama K, Igarashi T. A compound heterozygous mutation in the BSND gene detected in Bartter syndrome type IV. Pediatr Nephrol. 2006; 21 (2):190-3.

9. Kurtz LC, Karolyi L, Seyberth WH, Koch MC, Vargas R, Feldmann D, Vollmer M, Knoers NV, Madrigal G, GuayWoodford LM. A Common NKCC2 Mutation in Costa Rican Bartter's Syndrome Patients: Evidence for a Founder Effect. J Am Soc Nephrol. 1997; 8 (1): 1706-11.

10. García-Nieto V, Flores C, Luis-Yanes M, Gallego E, Villar J, Claverie-Martín F. Mutation G47R in the BSND gene causes Bartter syndrome with deafness in two Spanish families.Pediatr Nephrol. 2006; 21 (5): 643-8.

11. Birkenhäger R, Otto E, Schürmann MJ, Vollmer M, Ruf EM, Maier-Lutz I, Beekmann F, Fekete A, Omran H, Feldmann D, Milford DV, Jeck N, Konrad M, Landau D, Knoers NV, Antignac C, Sudbrak R, Kispert A, Hildebrandt F. Mutation of BSND causes Bartter syndrome with sensorineural deafness and kidney failure. Nat Genet. 2001; 29 (3): 310-4.

12. Gilbert WM. Amniotic Fluid Disorders. In: Gabbe S, Niebyl J, Simpson J, Landon M, Galan H, Jauniaux E, 
Driscoll D, Berghella V, Grobman W, edi-tors. Obstetrics: Normal and Problem Pregnancies. 7 Ed. Philadelphia, PA: Elsevier; 2017. p.786-94.

13. Mula R, Bennasar M, Palacio M, Goncé A, Puerto B. Àrea de Medicina Fetal, Servei de Medicina Materno-fetal. Institut Clínic de Ginecologia, Obstetrícia i Neonatologia Hospital Clínic de Barcelona. Protocolo: Polihidramnios en gestación única. [online]; 2012. [Accessed 12 Dec 2019]. Available from:https://medicinafetalbarcelona.org/protocolos/es/patologia-fetal/polihidramnios.pdf.
14. Garnier A, Dreux S, Vargas-Poussou R. Bartter Syndrome Prenatal Diagnosis Based on Amniotic Fluid Biochemical Analysis. Pediatr Res. 2010; 67 (3): 300-3.

Received on November 8, 2020

Final version presented on January 31, 2021

Approved on March 1, 2021 